\title{
The Effect of Diet Control on the Leptin Levels in Diabetic Pregnant Women
}

\author{
Muna $\mathrm{KA}^{\mathrm{a}}$, Mokhtar $\mathrm{A}^{\mathrm{a}}$, Saad $M \mathrm{~A}^{\mathrm{b}}$, Ahmed $\mathrm{AA} \mathrm{A}^{\mathrm{b}}$, Akbar JB $\mathrm{B}^{\mathrm{c}}$ \\ aDepartment of Obstetrics and Gynecology, Kulliyyah of Medicine, International Islamic University Malaysia, \\ Kuantan, Pahang, Malaysia. \\ ${ }^{b}$ Department of Basic Medical Sciences, Kulliyyah of Medicine, International Islamic University Malaysia, \\ Kuantan Pahang, Malaysia. \\ 'Department of Biotechnology, Kulliyyah of Science, Institute of Oceanography and Maritime Studies (INOCEM), \\ IIUM, Kuantan, Pahang, Malaysia
}

\begin{abstract}
Introduction: Leptin is an adipokine that has strong correlation with the body mass index (BMI). Gestational diabetes mellitus (GDM) is a common medical complication associated with pregnancy. Leptin may lose its correlation with the body mass index (BMI) during diabetes due to hormonal rearrangement. Diet control is the first line management in GDM. Leptin reported to increase in pregnancy and further increases in diabetic patients during GDM screening. There is paucity in the reports concerning Leptin levels in GDM patients on diet control. The present study was aimed to evaluate the changes in maternal leptin in pregnancy complicated by GDM on diet control compared to the normal pregnancy in the 3rd trimesters by comparing the means and to find the correlation of Leptin with the body mass index in both groups. Methods: The study included 2 groups: normal pregnancy $(n=40)$ and pregnancy with GDM under diet control $(n=60)$ both groups are at 38-40 weeks of gestation. Leptin concentration in serum was measured in both groups and statistically tested using student $t$ test. The BMI were measured and correlated with the Leptin level in test groups. Results: the results indicated that Leptin will nearly triple in the third trimester $(38 \pm 30 \mathrm{ng} / \mathrm{ml})$ of pregnancy compared to the standard normal non-pregnant. Leptin level was significantly lower in diabetic women on diet control $(28 \pm 16 \mathrm{ng} /$ $\mathrm{ml})$ when compared with the non-diabetics $(38 \pm 30 \mathrm{ng} / \mathrm{ml})$. The hormone has no correlation with the age of the patients but have a positive correlation with the body mass index before and during pregnancy in both groups. Conclusion: Leptin is increasing in pregnancy as part of the physiological changes. Dieting can decrease Leptin level in diabetics' pregnant women. Diet can restore the hormonal dysregulation of Leptin. Assessment of Leptin level might be used as an indicator for good diet control during pregnancy.
\end{abstract}

KEYWORDS: Leptin, Gestational diabetes mellitus, diet control, pregnancy.

\section{INTRODUCTION}

Leptin is an endocrine mediators secreted mainly by the adipose tissue and is correlated with the body mass index (BMI). ${ }^{1}$ It is also secreted by the placenta during pregnancy ${ }^{2}$ and its level correlate well with the pre-pregnancy $\mathrm{BMI}$ rather than the BMI during pregnancy ${ }^{3}$ due to its interaction with other hormones that increases during pregnancy, such as; oestrogen, progesterone and human placental lactogen. Pregnant women will usually gain $0.45-0.5 \mathrm{~kg} /$ week starting from the second trimester. ${ }^{4-7}$ During pregnancy maternal

Corresponding author:

Dr. Muna Kh. Al-Kubaisi

Dept of O\&G, Kulliyyah of Medicine, International Islamic University Malaysia, Jalan Hospital Campus, 25150, Pahang, Malaysia. Phone: 0060179410865

E-mail:mkbaysi@gmail.com serum leptin level will increase and peaks at 28 weeks of gestation. ${ }^{8}$ It is well documented that Leptin is increased during pregnancy and thus the hyperleptinemia is the hallmark of mammalian pregnancy. ${ }^{5}$ The mean level of this hormone has been reported to be tripled during pregnancy when compared to the leptin level in non-pregnant women. ${ }^{3,9}$ Pregnancy is a state of insulin resistance that might overt gestational diabetes. Leptin has been reported to be increased at the time of diagnosing GDM during screening. ${ }^{6}$ The management of GDM will start usually by diet control. The treatment should be monitored by the blood sugar profile to assess the effectiveness of the dieting. Leptin levels are expected to be high in pregnant diabetic mothers as Leptin is correlated positively with insulin resistance. ${ }^{9}$

Leptin is also affected by dieting and fasting. A low caloric diet will decrease the Leptin level particularly in the long term dieting. ${ }^{7}$ There is paucity in the reports concerning Leptin level in GDM patient on diet control and it is not clear that which factor (age, weight, BMI etc.,) denominator has the major effect on Leptin in mothers with GDM. In this study, we compared Leptin level in non-diabetic pregnant women with the level of Leptin in diabetic pregnant women on diet control. 


\section{MATERIALS AND METHODS}

This is a cross-sectional study among women who were admitted to the Tengku Ampuan Afzan HTAA hospital, Kuantan, Malaysia. The target population were 60 women with gestational diabetes at 38-40 weeks gestation for induction of labour for diabetes under diet control. All the patients were with wellcontrolled blood sugar profile (BSP). The criteria of diagnosing gestational diabetes mellitus (GDM) was by modified oral glucose tolerance test (MOGTT) (fasting $>5.6 \mathrm{mmol} / \mathrm{l}, 2$ hours post $75 \mathrm{~g}$ glucose $>7.8 \mathrm{mmol} / \mathrm{l}$ ) at 26 weeks gestation and the blood sugar profile considered satisfactory when the four pre-brandial readings ranged between 4-6 $\mathrm{mmol} / \mathrm{l}$. The control group were 40 pregnant women, non-diabetic at 38-40 weeks gestation. Patients with hypertension, symptoms and signs of infection and patients under insulin therapy were excluded from both the groups.

The study protocol was approved by the Research Management Centre of International Islamic University of Malaysia, the Clinical Research Centre of the clinical institute and the national Institute of health. The clinical research forms and the blood samples were collected by trained medical staff from the International Islamic University of Malaysia.

After a written consent, the age, weight $(\mathrm{Kg})$ and height (meter) were measured in to obtain the body mass index (BMI). $5 \mathrm{ml}$ of venous blood was taken with plan tube, centrifuged and the serums were stored at $-80^{\circ} \mathrm{C}$ until analysis. Fasting serum Leptin were measured using ELISA kits.

\section{Data analysis}

Independent sample t-test was used to compare the means of control and treatment group. $\mathrm{P}<0.05$ was considered statistically significant at $95 \%$ confidant interval. Levene's post hoc test was used to check the equality of variance. Pearson correlation matrix was used to determine the significant correlation between leptin level and the BMI and other parameters. All data were analysed using Statistical Package for Social Science (SPSS v21) software program.

\section{RESULTS}

Leptin level was significantly higher in Control group compared to the treatment $(t=2.123 p=0.036[p<0.05])$ with the mean level of $38.04 \mathrm{ng} / \mathrm{ml}$ and $28.07 \mathrm{ng} / \mathrm{ml}$ in control and treatment groups respectively (Table 1). However, the patient age does not influence the leptin level in both the groups (Table 2). Leptin level showed positive correlation with the BMI at term in both groups which was apparent in pearson correlation and the regression analysis (Figure 1\& 2).

Table 1. Mean difference in leptin level between non diabetic pregnant women and diabetics on diet control.

\begin{tabular}{lllll}
\hline & $\mathrm{N}$ & Mean & Std. Deviation & Std. Error Mean \\
\hline Non diabetics & 40 & 38.0403 & 30.30133 & 4.79106 \\
$\begin{array}{l}\text { Diabetic on diet } \\
\text { control }\end{array}$ & 60 & 28.0725 & 16.48276 & 2.12791 \\
\hline
\end{tabular}

$t=2.123 p=0.036[p<0.05]$

Table 2. Effect of age group (below and above 35) on the leptin concentration in diabetic and non-diabetic patients

\begin{tabular}{lclll}
\hline Non diabetic Group & $\mathrm{N}$ & Mean & Std. Deviation & Std. Error Mean \\
\hline below 35 years & 33 & 37.5533 & 31.27856 & 5.44490 \\
Above 35 years & 7 & 40.3371 & 27.25532 & 10.30154 \\
\hline$t=-.218 p=0.829[p>0.05]$ & & & \\
\hline Diabetic group & $\mathrm{N}$ & Mean & Std. Deviation & Std. Error Mean \\
\hline Below 35 years & 39 & 30.6574 & 17.00568 & 2.72309 \\
Above 35 years & 21 & 23.2695 & 14.65409 & 3.19779 \\
\hline
\end{tabular}

$t=1.681 p=0.098[p>0.05]$ 


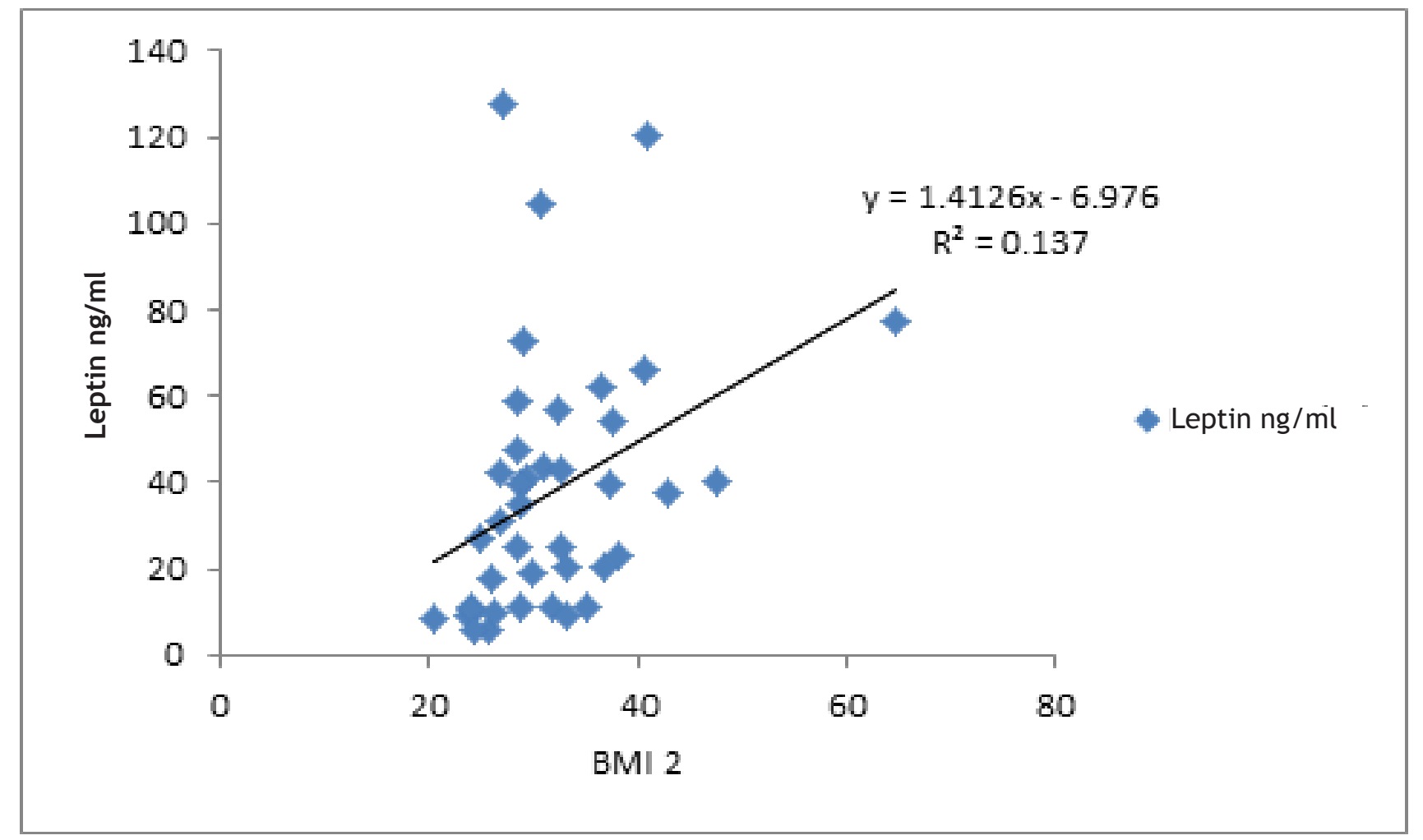

Figure 1. The correlation between Leptin and BMI at term in the non-diabetic pregnant women.

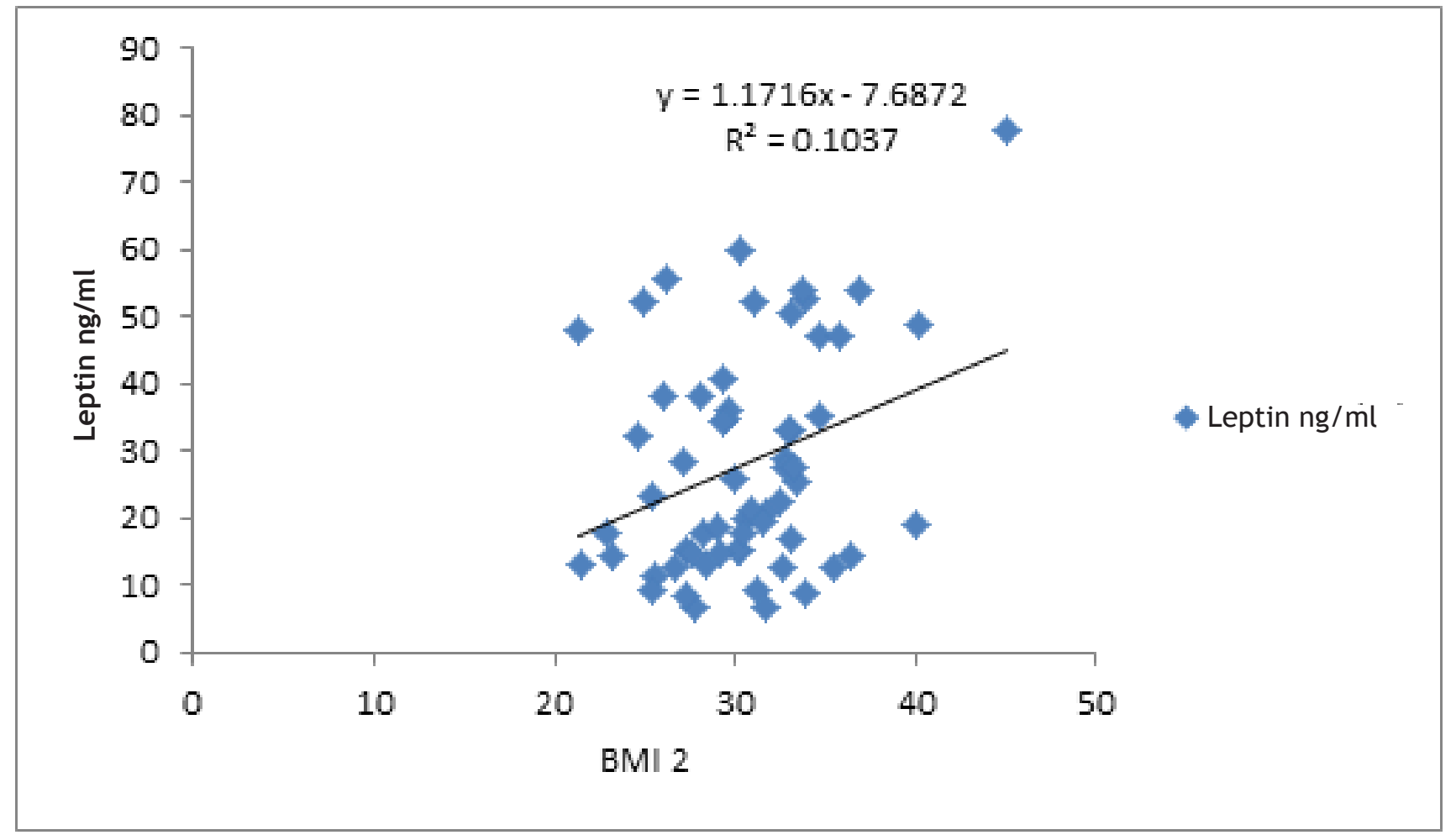

Figure 2. The correlation between Leptin and BMI at term in the diabetic pregnant women on diet control 


\section{DISCUSSION}

It is reported that the leptin level in non-pregnant female was in the range of $6-12 \mathrm{ng} / \mathrm{ml}{ }^{1,7}$ Data presented in this study demonstrated that the leptin level will triple during pregnancy in the non-diabetic group at term as our study found a mean level of $38 \pm 30 \mathrm{ng} / \mathrm{ml}$. Similar results were observed by other researchers. 3,9,10 Factors that can contribute to this increase might be; the hyperdynamic status with increasing basal metabolic rate during pregnancy, accumulation of fat to adapt the pregnancy, hormones that antagonise insulin namely oestrogen and human placental lactogen and placental production of Leptin as it has been reported that placenta produces leptin. ${ }^{11}$ The increase in Leptin level might be considered as one of the physiological changes of pregnancy to overcome the insulin resistance status as some studies showed that leptin might control insulin resistance by increasing the peripheral sensitivity to the insulin. ${ }^{12,13}$ Hence, it can be conclude that the increase in Leptin level might be considered as part of the hormonal profile during pregnancy.

During diabetes including the GDM, Leptin was reported to be higher than the non- diabetic status independent to the BMI.6,8,9,14 However, no difference in Leptin level in diabetic and non-diabetic pregnant women has been reported. ${ }^{3,10,15}$ Most of these studies didn't mention the mode of treatment in the study group. Pregnancy associated with high circulating levels of both oestrogen and progesterone that have been proposed to cause insulin resistance by reducing the cellular content of insulin receptor substrate proteins (IRSs) results in reduction of insulin-stimulated signalling cascades. ${ }^{16}$ Other studies measured the Leptin level at the time of screening for diabetes during pregnancy and found the level is significantly higher in GDM patients compare to the non-diabetics. ${ }^{1,6,9}$ The overall sight; Leptin will increase in pregnant and nonpregnant diabetic.

In this study, the GDM patients were already established on diet controlled and they were monitored by the blood sugar profile (BSP); Leptin level was found to be lower in pregnant women with gestational diabetes on diet control, the mean level was $28 \pm 16 \mathrm{ng} / \mathrm{ml}$, it is significantly lower than the non-diabetics leptin level that is having normal diet. Low level of Leptin in patient on diet control had been reported by Amani. ${ }^{17}$ This decrease in the hormone level might be attributed to caloric restriction -specially on the long run- is known to decrease Leptin level. ${ }^{7,18}$

The overall view may be explained as; diabetes is a hyperinsulinemic status, the hyperinsulinemia will signal for leptin secretion and hence the leptin level will increase in uncontrolled diabetes to compensate for insulin resistance. Bringing down the hyerinsulinemia by diet control will bring down the Leptin level significantly. An individual with congenital hypoleptinemia have low sensitivity to insulin hence they will develop diabetes, treatment with physiological leptin will increase tissue sensitivity to the secreted insulin. ${ }^{12}$

Leptin have a strong correlation with BMI and this fact had been documented, Leptin were extensively reported to correlate positively with the body mass index in non-pregnant individuals, ${ }^{19,20,21}$ this correlation had been also demonstrated in the pregnant women, ${ }^{15,22,23,24}$ this positive correlation will be lost in diabetic individuals. ${ }^{15,25}$ Many had reported a dysregulation of Adipokines during diabetes in pregnant and non-pregnant individuals. ${ }^{8,14}$ In our study, both groups showed a positive correlation between initial and final BMI of the patients with leptin concentration. There was a strong positive correlation between serum leptin level and maternal BMI in normal pregnancy at term and there was a moderate correlation between Leptin and the BMI in the diabetic group on diet control during the study. Thus we can conclude that dieting can help in correcting the hormonal derangement that occurs during GDM with good diet control by bringing down the hyperinsulinaemia.

One Limitation of the study is that the leptin level was not determined the leptin in uncontrolled diabetes to compare it with the well-controlled studied group. This could be a next step to investigate patients presented with suboptimal diet control.

\section{CONCLUSION}

Leptin level was significantly higher in pregnant women at term compare to the non-pregnant women. This could be part of the physiological changes during pregnancy. Leptin correlated to the BMI and it will keep this correlation during pregnancy and in GDM patients with good diet control. Measuring Leptin level could be utilized to reflect a good diet control during pregnancy. However, further investigation on the leptin level in diabetic patient on diet with unsatisfactory BSP may reveal this confusion.

\section{Acknowledgment}

The authors would like to acknowledge the patients and healthy subjects who willingly participated in the study. This work was supported by research grant (IIUM Endowment B, Grant Number: 11-278-0756) from the International Islamic University Malaysia.

\section{REFERENCES}

1. Anshu K, Tanu A, Prashant C, et al. Plasma leptin levels and Body Mass Index in North Indian subjects: correlation with insulin resistance. Journal of Advance Researches in Biological Sciences 2013; 5:59-62.

2. Maymó JL, Pérez AP, Gambino Y, et al. Review: Leptin gene expression in the placenta--regulation of a key hormone in trophoblast proliferation and survival. Placenta 2011; 32:S146-53. 
3. Maple-Brown L, Ye C, Hanley AJ, et al. Maternal pregravid weight is the primary determinant of serum leptin and its metabolic associations in pregnancy, irrespective of gestational glucose tolerance status. J Clin Endocrinol Metab 2012; 97:4148-55.

4. The American College of Obstetrician and Gynecologist Committee Opinion Number 508, January 2013: weight gain during pregnancy. Obstet Gynecol 2013; 121:210-2.

5. Henson MC, Castracane VD. Leptin in Pregnancy: An Update. Biol Reprod 2006; 74:218-29.

6. Soheilykhah S, Mojibian M, Rahimi-Saghand S, Rashidi M, Hadinedoushan H. Maternal serum leptin concentration in gestational diabetes. Taiwan J Obstet Gynecol 2011; 50:149-53.

7. Weigle DS, Duell PB, Connor WE, et al. Effect of fasting, refeeding, and dietary fat restriction on plasma leptin levels. J Clin Endocrinol Metab 1997; 82:561-5.

8. Miehle K, Stepan H, Fasshauer M. Leptin, adiponectin and other adipokines in gestational diabetes mellitus and pre-eclampsia. Clin Endocrinol 2012; 76:2-11.

9. Skvarca A, Tomazic M, Blagus R, Krhin B, Janez A. Adiponectin/leptin ratio and insulin resistance in pregnancy. J Int Med Res 2013; 41:123-8.

10. Horosz E, Bomba-Opon DA, Szymanska M, Wielgos M. Third trimester plasma adiponectin and leptin in gestational diabetes and normal pregnancies. Diabetes Res Clin Pract 2011; 93:350-6.

11. Masuzaki H, Ogawa Y, Sagawa N, et al. Nonadipose tissue production of leptin: leptin as a novel placenta-derived hormone in humans. Nat Med 1997; 3:1029-33.

12. Sarath R, Rajkumar B. Role of Leptin in Diabetes Mellitus. Indian Journal of Fundamental and Applied Life Sciences 2011; 1:209-14.

13. Banerji MA, Faridi N, Atluri R, Chaiken RL, Lebovitz HE. Body composition, visceral fat, leptin, and insulin resistance in Asian Indian men. J Clin Endocrinol Metab 1999; 84:137-44.

14. Fischer S, Hanefeld M, Haffner SM, et al. Insulinresistant patients with type 2 diabetes mellitus have higher serum leptin levels independently of body fat mass. Acta Diabetol 2002; 39:105-10.

15. Mokhtari M, Hashemi M, Yaghmaei M, et al. Evaluation of the serum leptin in normal pregnancy and gestational diabetes mellitus in Zahedan, Southeast Iran. Arch Gynecol Obstet. 2011 Sep;284(3):539-42.

16. Garcia-Arencibia M, Molero S, Davila N, Carranza MC, Calle C. 17beta-Estradiol transcriptionally represses human insulin receptor gene expression causing cellular insulin resistance. Leuk Res 2005; 29:79-87.

17. Noureldeen AF, Qusti SY, Al-Seeni MN, Bagais MH. Maternal Leptin , Adiponectin, Resistin, Visfatin and Tumor Necrosis Factor-Alpha in normal and gestational diabetes. Indian J Clin Biochem 2014; 29:462-70.

18. Ostlund RE Jr, Yang JW, Klein S, Gingerich R.
Relation between plasma leptin concentration and body fat, gender, diet, age, and metabolic covariates. J Clin Endocrinol Metab 1996; 81: 3909-13.

19. Yamada M, Matsuzaki T, Iwasa T, et al. Serum leptin levels in women throughout life; relationship to body mass index and serum estradiol levels. Jpn J Reprod Endocrinol 2003; 8:55-60.

20. Al Maskari MY, Alnaqdy AA. Correlation between serum leptin levels, body mass index and obesity in omanis. Sultan Qaboos University Medical Journal 2006; 6:27-31.

21. Jaleel F, Jaleel A, Rahman MA, Alam E. Comparison of adiponectin, leptin and blood lipid levels in normal and obese postmenopausal women. J Pak Med Assoc 2006; 56:391-4.

22. Festa A, Shnawa N, Krugluger W, et al. Relative hypoleptinaemia in women with mild gestational diabetes mellitus. Diabet Med 1999; 16:656-62.

23. Stock SM, Bremme KA. Elevation of plasma leptin levels during pregnancy in normal and diabetic women. Metabolism 1998; 47:840-3.

24. Lakho GR, Nazir K, Chundrigar T, Jabeen N, Qureshi MA. Serum leptin levels in pregnant Pakistani females: relationship with body mass index and placental weight. J Pak Med Assoc 2001; 51:32-6.

25. Tatti P, Masselli L, Buonanno A, Di Mauro P, Strollo F. Leptin levels in diabetic and nondiabetic subjects. Endocrine 2001; 15:305-8. 